Syntax Literate : Jurnal Ilmiah Indonesia p-ISSN: 2541-0849 e-ISSN: 2548-1398

Vol. 5, No. 4 April 2020

\title{
PENGARUH BUDAYA ORGANISASI DAN MOTIVASI TERHADAP PRESTASI KERJA KARYAWAN PADA PT. BPR WAHANA SENTRA ARTHA KABUPATEN MAJALENGKA
}

Ade Sobariah Hasanah

Sekolah Tinggi Ilmu Ekonomi (STIE) STMY Majalengka

Email: ade.sobariah85@gmail.com

\section{Abstract}

Low employee performance is a problem that cannot be ignored, because it will adversely affect the development of the company. The existence of organizational culture and work motivation in a company can affect the work performance of its employees. The purpose of this study was to determine the effect of organizational culture and motivation on employee work performance at PT. BPR Wahana Sentra Artha Kadipaten Majalengka District. The method used is a survey. Data collection techniques using a questionnaire. The population is 68 people, because of the relatively small number, the entire population will be examined so that it is a census study. Research data were analyzed using SPSS software version 23. The results of this study indicate that there is a positive and significant influence of organizational culture on employee work performance by $2.2 \%$. Motivation has a positive and significant effect on employee work performance by $60.0 \%$. Organizational culture and motivation together have a positive and significant effect on employee work performance by $71.0 \%$. In enhancing organizational culture towards employee work performance, employees must be able to show their level of participation in the organization, respond to changes in the external and internal environment, and must be firm and focus on things that are considered important by the organization concerned. To increase motivation for employee work performance, it can be done by fulfilling the need for achievement, affiliated needs, the need for power, the need for appreciation, and the fulfillment of employee self-actualization needs.

Keywords: Organizational Culture, Motivation, and Work Performance of Employees

\begin{abstract}
Abstrak
Prestasi kerja karyawan yang rendah merupakan masalah yang tidak bisa dibiarkan begitu saja, karena akan berdampak buruk terhadap perkembangan perusahaan. Keberadaan budaya organisasi dan motivasi kerja pada sebuah perusahaan dapat berpengaruh pada prestasi kerja karyawannya. Tujuan penelitian ini untuk mengetahui pengaruh budaya organisasi dan motivasi terhadap prestasi kerja karyawan pada PT. BPR Wahana Sentra Artha Kadipaten Kabupaten Majalengka. Metode yang digunakan adalah survey. Teknik pengumpulan data menggunakan kuesioner. Populasi berjumlah 68 orang, karena jumlah yang relatif sedikit, maka seluruh populasi akan diteliti sehingga merupakan penelitian sensus. Data penelitian dianalisis dengan menggunakan software SPSS versi 23. Hasil penelitian
\end{abstract}


ini menunjukan bahwa terdapat pengaruh positif dan signifikan budaya organisasi terhadap prestasi kerja karyawan sebesar 2,2\%. Motivasi berpengaruh positif dan signifikan terhadap prestasi kerja karyawan sebesar $60,0 \%$. Budaya organsiasi dan motivasi secara bersama-sama berpengaruh positif dan signifikan terhadap prestasi kerja karyawan sebesar 71,0\%. Dalam meningkatkan budaya organisasi terhadap prestasi kerja karyawan, karyawan harus dapat menunjukkan tingkat partisifasi mereka dalam organisasi, memberikan respon perubahan pada lingkungan eksternal maupun internal, dan harus teguh serta fokus pada hal-hal yang dianggap penting oleh organisasi yang bersangkutan. Untuk meningkatkan motivasi terhadap prestasi kerja karyawan, dapat dilakukan dengan cara pemenuhan kebutuhan akan prestasi, kebutuhan berafiliasi, kebutuhan akan kekuasaan, kebutuhan akan penghargaan, dan pemenuhan kebutuhan aktualisasi diri karyawan.

Kata kunci : Budaya organisasi, motivasi dan prestasi kerja karyawan

\section{Pendahuluan}

Suatu perusahaan didirikan karena mempunyai tujuan yang ingin dicapai. Dalam mencapai tujuannya setiap perusahaan dipengaruhi oleh perilaku dan sikap orang-orang yang ada di perusahaah tersebut. Manajemen sumber daya manusia merupakan pilar yang memiliki tuntutan utama bagi organisasi (Pane, 2019), dalam mendukung pola penentuan strategi dan kebijakan secara terpadu. Keberhasilan suatu organisasi, salah satunya dipengaruhi oleh budaya organisasi dan motivasi kerja karyawan. Budaya memberikan identitas bagi para anggota organisasi dan membangkitkan komitmen terhadap keyakinan dan nilai yang lebih besar dari dirinya sendiri. Meskipun ide-ide ini telah menjadi bagian budaya itu sendiri yang bisa datang dimanapun organisasi itu berada. Keberadaan budaya organisasi dalam sebuah perusahaan merupakan gambaran dari suatu pola yang ada dan dikembangkan serta dilaksanakan oleh seluruh anggota organisasi dengan tujuan agar organisasi dapat berjalan sesuai dengan aturan yang berlaku, sehingga apabila terdapat permasalahan dalam organisasi maka akan dapat diatasi dan ditangani oleh anggota organisasi tersebut (Lako, 2004).

Setiap anggota organisasi memiliki latar belakang budaya yang berbeda-beda, namun jika individu telah masuk ke dalam sebuah organisasi maka perbedaan tersebut akan dilebur sehingga membentuk satu kesatuan yang disebut budaya organisasi. Setiap individu akan dituntut untuk dapat bekerjasama dan berkontribusi terhadap perusahaan dimana mereka bergabung dengan satu visi yaitu bersama-sama mencapai tujuan perusahaan. Akan tetapi dalam berjalannya roda organisasi tidak menutup kemungkinan terdapat beberapa individu yang setuju dan tidak setuju terhadap budaya organisasi yang berjalan diperusahaan, hal ini dikarenakan budaya perusahaan bisa saja bertentangan dengan budaya yang sudah mereka miliki dalam kesehariannya.

Adapun motivasi merupakan sikap mental yang ditimbulkan oleh adanya suatu rangsangan yang mendorong manusia untuk melakukan sesuatu. Perangsang yang dimaksud merupakan mesin penggerak motivasi, sehingga menimbulkan pengaruh pada perilaku individu yang bersangkutan. Motivasi berperan sangat penting dalam 
meningkatkan prestasi kerja karyawan. Dengan adanya motivasi, karyawan akan senantiasa dirangsang untuk melakukan pekerjaan sesuai dengan tujuan perusahaan.

Timbulnya prestasi kerja karyawan salah satunya disebabkan adanya kesesuaian dari budaya organisasi diperusahaan dan motivasi kerja yang dimiliki karyawan sehingga dapat mendorong karyawan untuk dapat bekerja secara maksimal dan dalam jangka waktu yang lama. Oleh sebab itu, kegiatan pelayanan yang diberikan oleh karyawan PT. BPR Wahana Sentra Arha selalu memperhatikan kualitas dan kuantitas dari sumber daya manusianya sebagai cermin dari baiknya budaya organisasi yang ada pada perusahaan. Semakin baik tingkat budaya organiasi pada perusahaan akan mencerminkan semakin tinggi juga prestasi kerja dari karyawannya. Dan hal tersebut dijadikan pedoman baik oleh pimpinan maupun karyawan PT. BPR Wahana Sentra Artha untuk terus memberikan pelayanan prima pada nasabah.

Bertitik tolak dari permasalahan di atas, peneliti merasa tertarik untuk mengadakan penelitian lebih lanjut mengenai pelaksanaan budaya organsiasi dan motivasi dalam kaitannya dengan prestasi kerja karyawan sebagai bahan penelitian dengan judul: "Pengaruh Budaya Organisasi dan Motivasi terhadap Prestasi Kerja pada PT. BPR Wahana Sentra Artha Kabupaten Majalengka".

\section{Metode Penelitian}

Subjek dalam penelitian ini sebanyak 68 orang karyawan. Teknik pengumpulan data menggunakan instrument penelitian berupa angket, dan terlebih dahulu dilakukan uji instrumen dengan uji validitas dan uji reliabilitas. Sebelum melakukan pengujian hipotesis, terlebih dahulu dilakukan uji asumsi klasik untuk mengetahui apakah sampelsampel yang diambil berdistribusi normal atau tidak, yakni menggunakan uji asumsi klasik terdiri dari uji normalitas, uji multikolinearitas, uji autokorelasi, uji linearitas, dan uji heterokedastisitas. Setelah uji asumsi klasik terpenuhi, maka dilanjutkan pada analisa data menggunakan analisis jalur (path analysis) dengan bantuan software SPSS versi 23, dan untuk memudahkan uji hipotesis maka struktur hubungan antar variabel dijabarkan dalam sub struktur hubungan variabel penelitian yaitu menggambarkan pengaruh budaya organisasi dan motivasi terhadap prestasi kerja karyawan. 
Ade Sobariah Hasanah

\section{Hasil dan Pembahasan}

Berikut adalah hasil pengujian korelasi, regresi dan uji hipotesis dengan menggunakan software SPSS versi 23.

Tabel 1

Correlations

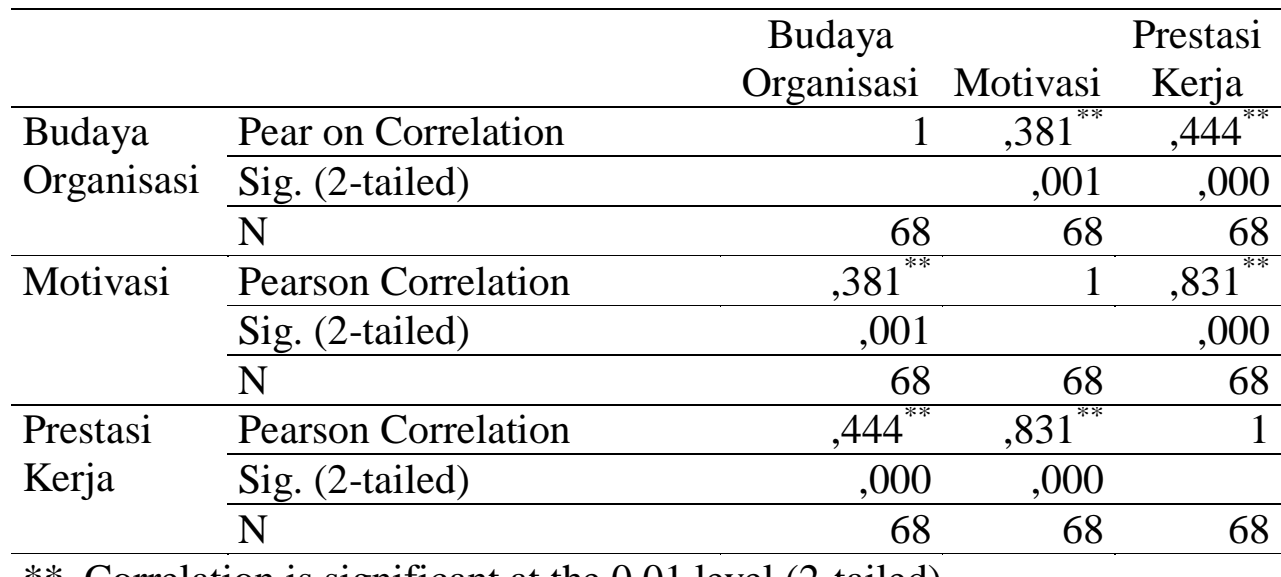

**. Correlation is significant at the 0.01 level (2-tailed).

Tabel 2

Model Summary

\begin{tabular}{llrrr}
\hline Model & $\mathrm{R}$ & $\mathrm{R}$ & Adjusted & \multicolumn{2}{c}{$\begin{array}{c}\text { Std. Error of the } \\
\text { Square }\end{array}$} & $\begin{array}{c}\text { R Square } \\
\text { Estimate }\end{array}$ \\
\hline 1 &, $843^{\mathrm{a}}$ &, 710 &, 701 & 3,655 \\
\hline
\end{tabular}

a. Predictors: (Constant), Motivasi , Budaya Organisasi

Tabel 3

ANOVA $^{\mathrm{a}}$

\begin{tabular}{|c|c|c|c|c|c|}
\hline Model & $\begin{array}{l}\text { Sum of } \\
\text { Squares }\end{array}$ & df & $\begin{array}{l}\text { Mean } \\
\text { Square }\end{array}$ & $\mathrm{F}$ & Sig. \\
\hline 1 Regression & 2124,051 & 2 & 1062,026 & 79,509 &, $000^{b}$ \\
\hline Residual & 868,228 & 65 & 13,357 & & \\
\hline Total & 2992,279 & 67 & & & \\
\hline
\end{tabular}

a. Dependent Variable: Prestasi Kerja

b. Predictors: (Constant), Motivasi , Budaya Organisasi

Tabel 4

Coefficients $^{\mathrm{a}}$

\begin{tabular}{|c|c|c|c|c|c|}
\hline \multirow[b]{2}{*}{ Model } & \multicolumn{2}{|c|}{$\begin{array}{c}\text { Unstandardized } \\
\text { Coefficients }\end{array}$} & \multirow{2}{*}{$\begin{array}{c}\text { Standardized } \\
\text { Coefficients } \\
\text { Beta }\end{array}$} & \multirow[b]{2}{*}{$\mathrm{t}$} & \multirow[b]{2}{*}{ Sig. } \\
\hline & B & $\begin{array}{l}\text { Std. } \\
\text { Error }\end{array}$ & & & \\
\hline 1 (Constant) & 3,297 & 4,289 & & ,769 &, 445 \\
\hline $\begin{array}{l}\text { Budaya } \\
\text { Organisasi }\end{array}$ & ,261 & , 127 & 149 & 2,056 & ,044 \\
\hline Motivasi & ,711 & ,066 & ,775 & 10,721 & ,000 \\
\hline
\end{tabular}


a. Dependent Variable: Prestasi Kerja

Diagram jalur hasil penelitian dijelaskan dalam gambar berikut:

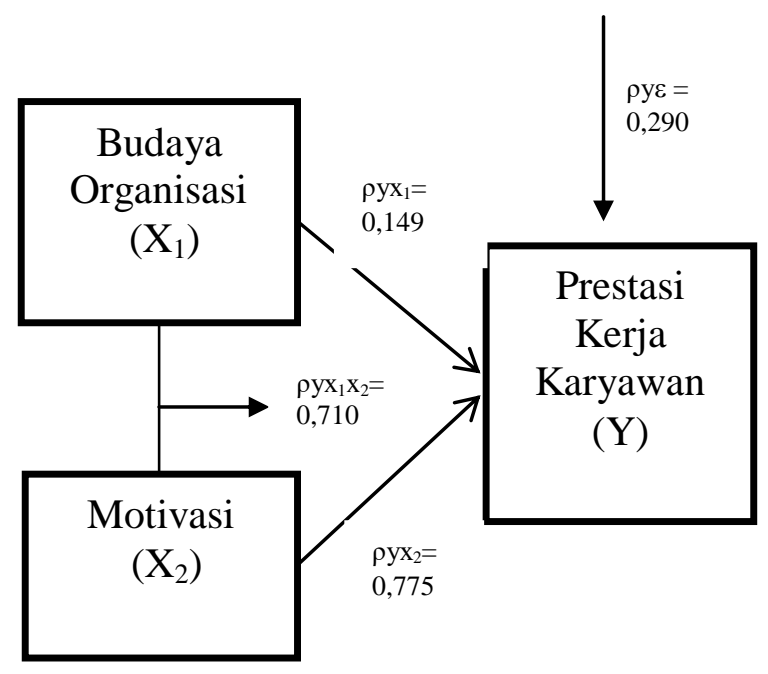

Gambar 1

Struktur Hubungan Kausal $X_{1}, X_{2}$, terhadap $Y$

Berdasarkan hasil perhitungan analisis jalur, maka memberikan informasi secara ringkas dan objektif pada tabel 5 sebagai berikut:

\section{Tabel 5}

Koefisien Jalur Budaya Organisasi $\left(\mathrm{X}_{1}\right)$; Motivasi $\left(\mathrm{X}_{2}\right)$; Prestasi Kerja (Y)

\begin{tabular}{|c|c|c|c|}
\hline \multirow{2}{*}{$\begin{array}{c}\text { Variabe } \\
1\end{array}$} & \multicolumn{2}{|c|}{ Kontribusi } & \multirow{2}{*}{$\begin{array}{c}\text { Konti } \\
\text { busi } \\
\text { Bersa } \\
\text { ma }\end{array}$} \\
\hline & $\begin{array}{c}\text { Langsun } \\
\mathrm{g}\end{array}$ & $\begin{array}{c}\text { Tidak } \\
\text { Langsun } \\
\mathrm{g}\end{array}$ & \\
\hline$\underset{\mathrm{Y}}{\mathrm{X}_{1} \rightarrow}$ & 0,149 & - & 0,149 \\
\hline $\begin{array}{c}\mathrm{X}_{2} \rightarrow \\
\mathrm{Y}\end{array}$ & 0,775 & - & 0,775 \\
\hline $\begin{array}{l}\mathrm{X}_{1} \mathrm{X}_{2} \\
\rightarrow \mathrm{Y}\end{array}$ & 0,710 & - & $\begin{array}{c}0,710 \\
\text { atau } \\
71,0 \% \\
\end{array}$ \\
\hline$\varepsilon$ & 0,290 & - & 0,290 \\
\hline $\begin{array}{c}\mathrm{X}_{1} \text { dan } \\
\mathrm{X}_{2}\end{array}$ & - & - & $\begin{array}{c}0,381 \\
\text { atau } \\
38,1 \%\end{array}$ \\
\hline
\end{tabular}

Sumber: hasil pengolahan peneliti

Berdasarkan pada Tabel 5 diatas, maka hasil penelitian secara objektif bahwa:

a) Kontribusi budaya organisasi $\left(\mathrm{X}_{1}\right)$ yang secara langsung mempengaruhi prestasi kerja $(\mathrm{Y})$ sebesar $(0,149)^{2}=0,022$ atau $2,2 \%$

b) Kontribusi motivasi $\left(\mathrm{X}_{2}\right)$ yang secara langsung mempengaruhi prestasi kerja $(Y)$ sebesar $(0,775)^{2}=0,600$ atau $60,0 \%$ 
c) Kontribusi budaya organisasi $\left(\mathrm{X}_{1}\right)$ dan motivasi $\left(\mathrm{X}_{2}\right)$ secara simultan yang secara langsung mempengaruhi prestasi kerja (Y) sebesar 0,710 $=71,0 \%$. Sisanya sebesar $0,290=29,0 \%$ dipengaruhi faktor-faktor lain yang tidak dijelaskan dalam penelitian.

\section{Pengaruh Budaya Organisasi Terhadap Prestasi Kerja}

Pengaruh budaya organisasi terhadap prestasi kerja karyawan pada uji hipotesis menunjukkan bahwa budaya organisasi berpengaruh positif dan signifikan terhadap prestasi kerja karyawan. Budaya organisasi berisi norma perilaku dan nilai-nilai yang dipahami dan dapat diterima oleh semua anggota yang ada dalam organisasi tersebut. Organisasi yang baik dapat memberikan gambaran keadaan yang baik pula, yang dapat membangun suasana kerja yang dinamis dan sehat sehingga dapat berdampak pada meningkatnya prestasi kerja karyawan. Semakin baiknya budaya orgasnisasi yang ada diperusahaan dapat dilihat dari semakin tingginya tingkat partisifasi karyawan dalam kegiatan perusahaan, karyawan memiliki kepedulian yang tinggi terhadap perubahan demi kemajuan perusahaan dan karyawan fokus pada tujuan untuk memajukan perusahaan. Semakin tinggi budaya organisasi maka akan semakin tinggi prestasi kerja karyawannya. Hal ini sejalan dengan hasil penelitian (Suwandi \& Si, 2008) yang menyatakan bahwa budaya organisasi berpengaruh positif terhadap prestasi kerja karyawan.

\section{Pengaruh Motivasi Terhadap Prestasi Kerja}

Pengaruh motivasi terhadap prestasi kerja karyawan pada uji hipotesis menunjukkan bahwa motivasi berpengaruh positif dan signifikan terhadap prestasi kerja karyawan. Motivasi kerja karyawan merupakan aset berharga yang dimiliki perusahaan yang dinilai dapat meningkatkan prestasi kerja karyawan, maka perusahaan harus berusaha agar karyawan yang ada diperusahaan dapat selalu menjaga dan meningkatkan motivasi kerjanya yaitu dengan cara memenuhi kebutuhan karyawan akan prestasi, afiliasi, mengarahkan pada pencapaian kekuasaan dan kedudukan terbaik pada perusahaan, memberikan penghargaan serta memberikan kesempatan untuk senantiasan mengembangkan diri sesuai dengan potensi yang dimiliki. Semakin tinggi motivasi kerja karyawan maka akan semakin tinggi pula prestasi kerja karyawan. Hal ini didukung oleh hasil penelitian yang dilakukan oleh (Meilani \& Suryalena, 2018) yang mengatakan bahwa motivasi memiliki pengaruh yang positif dan signifikan terhadap prestasi kerja karyawan.

3. Pengaruh Budaya Organisasi dan Motivasi Terhadap Prestasi Kerja Karyawan

Pengaruh budaya organisasi dan motivasi terhadap prestasi kerja karyawan pada uji hipotesis menunjukkan bahwa budaya organisasi dan motivasi berpengaruh positif dan signifikan terhadap prestasi kerja karyawan. Budaya organisasi dan motivasi kerja karyawan yang baik dapat menjadi pendorong meningkatnya prestasi kerja karyawan, sehingga menunjang pula pada pencapaian tujuan dan keberhasilan perusahaan. Sebaliknya jika budaya organisasi dan motivasi kerja menurun maka 
akan menghambat perusahaan dalam mencapai tujuannya. Hal ini didukung oleh hasil penelitian yang dilakukan oleh (Djaitun, Margono, \& Irawan, 2017) yang menjelaskan bahwa budaya organisasi dan motivasi berpengaruh positif dan signifikan terhadap prestasi kerja pegawai.

\section{Kesimpulan}

Terdapat pengaruh positif dan signifikan dari budaya organisasi terhadap prestasi kerja karyawan. Artinya semakin tinggi tingkat budaya organisasi maka semakin tinggi pula tingkat prestasi kerja karyawan. Sebaliknya rendahnya tingkat budaya kerja rendah pula tingkat prestasi kerja karyawan.

Terdapat pengaruh positif dan signifikan dari motivasi terhadap prestasi kerja karyawan. Artinya semakin tinggi tingkat motivasi maka semakin tinggi pula tingkat prestasi kerja karyawan. Sebaliknya rendahnya tingkat motivasi rendah pula tingkat prestasi kerja karyawan.

Terdapat pengaruh positif dan signifikan dari budaya organisasi dan motivasi terhadap prestasi kerja karyawan. Artinya semakin tinggi budaya organisasi dan motivasi maka semakin tinggi pula tingkat prestasi kerja karyawan. Sebaliknya rendahnya tingkat budaya organisasi dan motivasi rendah pula tingkat prestasi kerja karyawan. 
Ade Sobariah Hasanah

\section{BIBLIOGRAFI}

Djaitun, Siti, Margono, Anthonius, \& Irawan, Bambang. (2017). Pengaruh Faktor Budaya Organisasi dan Motivasi Terhadap Prestasi Kerja Pegawai pada Dinas Perhubungan Provinsi Kalimantan Timur. Jurnal Administrative Reform (JAR), 1(3), 582-595.

Lako, Andreas. (2004). Kepemimpinan dan Kinerja Organisasi Isu Teori dan Solusi. Yogyakarta: Amara Books, 80.

Meilani, Nely, \& Suryalena, Suryalena. (2018). Pengaruh Pemberian Motivasi dan Disiplin Kerja terhadap Prestasi Kerja Karyawan Kantor (Studi pada PT. Andika Permata Sawit Lestari Pekanbaru). Riau University.

Pane, Diapari Sosagaon Putra. (2019). Pengaruh Budaya Organisasi, Kepemimpinan, Lingkungan Kerja dan Motivasi Sebagai Variabel Intervening Terhadap Kinerja Dosen Politeknik di Kota Bekasi. Syntax Literate; Jurnal Ilmiah Indonesia, 4(9), 114.

Suwandi, Basrowi Dan, \& Si, M. (2008). Memahami Penelitian Kualitatif Jakarta: PT. Reneka Cipta. 